\title{
Pulicaria odora essential oil: a potential source of eco- friendly antioxidants and allelochemicals
}

\author{
Manal Zefzoufi ${ }^{1}$, Rabiaa Fdil ${ }^{1,}{ }^{*}$, Hafida Bouamama ${ }^{2}$, Abdelkarim Mouzdahir ${ }^{1}$, Khadija Sraidi ${ }^{1}$ and \\ Amina Abouzaid ${ }^{1}$ \\ ${ }^{1}$ Laboratory of Bioorganic Chemistry, Department of Chemistry, University Chouaïb Doukkali, \\ El Jadida, Morocco \\ ${ }^{2}$ Laboratory of Bioorganic macromolecular chemistry, Department of Biology, University Cadi Ayyad, \\ Marrakech, Morocco
}

\begin{abstract}
Several plants are potential sources of natural antioxidants and can also stimulate or inhibit the germination and growth of weeds due to the production of secondary metabolites. Pulicaria odora, medicinal and aromatic plant, spontaneous and widespread in Morocco, is widely used by the local population for its medicinal properties. In this study, allelopathic effects and antioxidant activities of P. odora roots essential oil (EO), and the main components, at different concentrations were investigated. The EO was isolated by hydrodistillation using a Clevenger apparatus. GC analysis of the EO indicated the presence of 75 volatile compounds. Among them two accounted for $89.96 \%$ of the oil. The EO was then subjected to column chromatography on silica gel. Two major constituents were isolated and identified by ${ }^{1} \mathrm{H}$ NMR, ${ }^{13} \mathrm{C}$ NMR as isobutyric acid 2-isopropyl-4-methylphenylester and 2-isopropyl-4-methylphenol. Following the results obtained by DPPH, $\mathrm{H}_{2} \mathrm{O}_{2}$ and FRAP methods, EO and its main components possess an interesting antioxidant effect. The significantly $(\mathrm{p}<0.05)$ highest antioxidant properties were exhibited by the phenolic compound followed by EO, whereas lowest from isobutyric acid 2-isopropyl-4-methyl-phenylester. The allelopathic effect of EO and its main components at different concentrations $(7.81-500 \mu \mathrm{g} / \mathrm{mL})$ was also tested against two forage species. Data obtained showed that EO, and its two major compounds inhibited significantly $(\mathrm{p}<0.05)$ seeds growth of both tested plants $(M$. sativa and $M$. falcata). A dose-response relationship was found in seed germination and seedling growth inhibition of the two tested plants. Overall, the phenolic component 2-isopropyl-4-methylphenol exhibited the highest phytotoxicity. Isobutyric acid 2-isopropyl-4-methyl-phenylester and EO have moderate phytotoxic effects on the growth of the two seeds essayed. In addition to that, results indicated that the phytotoxic effect of the EO (or its main compounds) also depended on the tested species.
\end{abstract}

Keywords: Pulicaria odora; Essential oil; Antioxidant capacity; Allelopathic potential.

\section{Introduction}

The Pulicaria genus belongs to the Asteraceae family, tribe Inuleae, and is represented by more than 100 species widespread all around the world and in the Mediterranean area, particularly ${ }^{1}$. Previous investigations of this genus showed the occurrence of several secondary metabolites such as monoterpenes, sesquiterpenes, diterpenoids, triterpenoids, flavonoids, and phenolic derivatives ${ }^{1-4}$. Various biological activities have been reported for some species of Pulicaria genus, such as antibacterial, antifungal, antioxidant ${ }^{4-7}, \quad$ cytotoxic, anticarcinogenic, antispasmodic and antihistaminic properties ${ }^{1}$. According to Touati ${ }^{8}$, various extracts from leaves and roots of Algerian P. odora, namely acetone, methanol, and chloroform extracts, showed moderate antibacterial activities against the Gramnegative bacteria (Escherichia coli and Pseudomonas

*Corresponding author: Rabiaa Fdil

Email address: fdilrabia@gmail.com

DOI: http://dx.doi.org/10.13171/mjc10602006301405rf aeruginosa). In contrast, the Gram-positive bacteria (Bacillus subtilis and Staphylococcus aureus) showed more sensitivity against these extracts.

In our previous research ${ }^{9}$, we reported that aqueous extract and organic extracts, namely methanol, dichloromethane, ethyl acetate, and butanol, from the roots of $P$. odora possessed antioxidant activity. The methanol, ethyl acetate, and butanol extracts exhibited a strong antioxidant activity and had the most potent scavenging ability of DPPH radical. We have also found that all the studied extracts from $P$. odora roots inhibited, at tested concentrations, the seed germination, radical and hypocotyl length of $M$. sativa and $M$. falcata, thus, the tested extracts have an allelopathic potential ${ }^{9}$. To our knowledge, there are only two reports on EO of Pulicaria odora. These two works reported isolation, identification, and 
antimicrobial activities of the EO and its two major volatile compounds ${ }^{2,3}$.

The EO from the roots of $P$. odora showed in vitro antimicrobial activity on Staphylococcus aureus, Streptococcus pyogenes, Vibrio cholera, and Candida albicans ${ }^{2}$. Also, P. odora roots EO is powerfully effective on Streptococcus $C$, Bacillus cereus, Enterococcus faecalis, and Pseudomonas vulgaris $^{3}$. P. odora roots are often used in Moroccan ethnomedicine to treat intestinal disorders, menstrual cramps, back pain, and as a popular natural remedy for the common cold and chills. The roots of $P$. odora are also used as a spice appreciated for its flavor to perfume bread and meat ${ }^{2}$. The use of some existing synthetic products such as antioxidants, pesticides, etc. has been restricted in recent years, due to their potentially toxic and detrimental effects on agroecosystems and human health. Medicinal and aromatic plants are potential sources of natural antioxidants. They can also act positively or negatively by their allelopathic potential on the germination and growth of weeds through secondary metabolites such as phenolics, alkaloids, flavonoids, and terpenoids. In the present work, EO of $P$. odora roots was evaluated for antioxidant and allelopathic effects on two forage species. To the best of our knowledge, there is no previous report on allelopathic and/or antioxidant effects neither of the studied EO nor on its main components.

\section{Materials and methods}

\subsection{Plant material}

The plant $P$. odora was collected from Ourika, on the East of Marrakech city (Morocco). Professor Mohammed Fennane confirmed the authenticity of the plant from the Scientific Institute (Rabat, Morocco). A Specimen (RAB No. 65346) was deposited in the botanic department of this Institute. The collected fresh root of this species was washed under running tap water, shade dried at room temperature and powdered.

\subsection{Extraction of essential oil (EO)}

$P$. odora roots $(3 \mathrm{~kg})$ were subjected to hydrodistillation for $4 \mathrm{~h}$ using a Clevenger type apparatus; yellow oil with a strong and pleasant aromatic odor was yielded. The EO was collected, dried over anhydrous sodium sulfate, and stored at $-10^{\circ} \mathrm{C}$ in an airtight container until used. The yield of the oil was calculated in relation to the dry weight of the plant.

\subsection{Gas chromatography (GC) analysis}

The GC was carried out with a Thermo gas chromatograph (model 8000). A non-polar HeweltPackard OV-17 capillary column (25 m long $\times$ $0.25 \mathrm{~mm}$ i.d., Film thickness $0.25 \mathrm{~m}$ ) was employed for the analysis. The column temperature program was $60^{\circ} \mathrm{C}$ for $6 \mathrm{~min}$, with $5^{\circ} \mathrm{C}$ increases per minute to $150^{\circ} \mathrm{C}$, which was maintained for $10 \mathrm{~min}$. The carrier gas was helium at a flow rate of $2 \mathrm{~mL} / \mathrm{min}$ (splitless mode). The detector and injector temperatures were maintained at 250 and $225^{\circ} \mathrm{C}$, respectively.

2.4. Fractionation and isolation of the major components of $\boldsymbol{P}$. odora essential oil (EO)

The EO (4.4 g) was subjected to open column chromatography on silica gel using n-hexane- diethyl ether mixtures with increasing polarity to yield 7 fractions. Fraction II (2.47 g, 100\% n-hexane) and fraction $\mathrm{V}(0.8 \mathrm{~g}, 100 \% \mathrm{n}$-hexane) gave pure known compounds $\underline{1}$ (isobutyric acid 2-isopropyl-4-methylphenylester) and $\underline{\mathbf{2}}$ (2-isopropyl-4-methylphenol) respectively, while fraction I (50 $\mathrm{mg}, 100 \%$ n-hexane), fraction III (20 mg, 100\% n-hexane), fraction IV (170 mg, 100\% n-hexane), fraction VI (780 mg, n-hexane / diethyl ether (98:2)) and fraction VII (60 mg, n-hexane / diethyl ether (97:3)) were mixtures. The structures of pure compounds $\underline{\mathbf{1}}$ and $\underline{\mathbf{2}}$ were established by ${ }^{1} \mathrm{H}$ NMR $\left(300 \mathrm{MHz}, \mathrm{CD}_{3} \overline{\mathrm{Cl}}_{3}\right)$ and ${ }^{13} \mathrm{C} \mathrm{NMR}\left(75 \mathrm{MHz}, \mathrm{CD}_{3} \mathrm{Cl}_{3}\right)$ data.

\subsection{Total phenolic content}

The total phenolic content of $P$. odora EO was evaluated using a modified colorimetric method described previously by Singleton and Rossi ${ }^{10}$. $0.50 \mathrm{~mL}$ of $(1 \mathrm{mg} / \mathrm{mL})$ of the oil in methanol was mixed with $0.25 \mathrm{~mL}$ of Folin-Ciocalteau reagent after that $3.0 \mathrm{~mL}$ of distilled water was added. Immediately, $0.75 \mathrm{~mL}$ of sodium carbonate $\mathrm{NaCO}_{3}(20 \%)$ and 0.95 $\mathrm{mL}$ of distilled water was added. The mixture was shaken well and incubated in the dark for $30 \mathrm{~min}$ at $37^{\circ} \mathrm{C}$ for the development of color. The absorbance was read at $765 \mathrm{~nm}$. The measurement was compared to a standard curve prepared with a gallic acid solution (Sigma Chemical). The total phenolic content in the plant oil was expressed as milligrams of gallic acid equivalent per gram of dry weight (mg GAE/ g DW).

\subsection{Antioxidant assays \\ 2.6.1. DPPH assay}

The ability of $P$. odora (EO and its two major compounds $\underline{\mathbf{1}}$ and $\underline{\mathbf{2}}$ ) to scavenge the $\mathrm{DPPH}^{\circ}$ radical was evaluated according to the method of Sudha ${ }^{11}$ with some modifications. $1 \mathrm{~mL}$ of various concentrations of each sample in methanol (5-100 $\mu \mathrm{g} / \mathrm{mL}$ ) was mixed with $1 \mathrm{~mL}$ of $0.2 \mathrm{mM} \mathrm{DPPH}$ fresh solution in methanol. The mixture was shaken vigorously and left to stand in the dark at room temperature for $30 \mathrm{~min}$. The absorbance of the reaction mixture was measured at $517 \mathrm{~nm}$. Negative control was prepared as above, but without the $P$. odora samples and methanol was used for the baseline correction. Butylated hydroxytoluene (BHT) was used as a standard antioxidant. The percentage of $\mathrm{DPPH}^{\cdot}$ radical scavenging was calculated by using the following formula: $\mathrm{DPPH}^{\circ}$ scavenging effect (\% of inhibition $)=\left(\mathrm{A}_{0}-\mathrm{A}_{1}\right) \times 100 / \mathrm{A}_{0}$ where $\mathrm{A}_{0}$ is the absorbance of the control (without the sample), and $A_{1}$ is the absorbance of the sample. Scavenging activity was expressed as $\mathrm{IC}_{50}$ (effective concentration in $\mu \mathrm{g} / \mathrm{mL}$ of samples or standard that reduces the absorbance of DPPH by $50 \%$ when compared with 
negative control). The experiment was carried out in triplicate.

\subsection{2. $\mathrm{H}_{2} \mathrm{O}_{2}$ radical scavenging assay}

Hydrogen peroxide scavenging activity of $P$. odora EO was estimated according to the method of Ruch ${ }^{12}$ with slight modifications. A solution of hydrogen peroxide $(40 \mathrm{mM})$ was prepared in phosphate buffer (pH 7.4). The $P$. odora samples $(0.4 \mathrm{~mL})$ at various concentrations in methanol $(5-100 \mu \mathrm{g} / \mathrm{mL})$ were added to a hydrogen peroxide solution $(0.6 \mathrm{~mL})$. The reaction mixture was left to stand at room temperature for $10 \mathrm{~min}$. The absorbance of hydrogen peroxide at $230 \mathrm{~nm}$ was determined 10 minutes later against a blank solution containing the phosphate buffer without hydrogen peroxide. Ascorbic acid was used as the reference compound. The percentage of $\mathrm{H}_{2} \mathrm{O}_{2}$ scavenging was calculated as follows: Percent scavenging $=\left[\left(\mathrm{A}_{0}-\mathrm{A}_{1}\right) / \mathrm{A}_{0}\right] \times 100 \%$, where $\mathrm{A}_{0}$ is the absorbance of the control (without the sample), and $\mathrm{A}_{1}$ is the absorbance of the sample ( $P$. odora or ascorbic acid). The samples concentration required to bring $50 \%$ of scavenging $\left(\mathrm{IC}_{50}\right)$ was calculated from the interpolation of the curves plotted for percentage inhibition against the respective concentrations. Experiments were performed in triplicate.

\subsubsection{Reducing power activity (FRAP)}

Reducing the power activity of $P$. odora samples was measured according to the method of Oyaizu ${ }^{13}$ with few modifications. Various concentrations in methanol $(5-250 \mu \mathrm{g} / \mathrm{mL})$ of plant samples were mixed with $2.5 \mathrm{~mL}$ of $0.2 \mathrm{~mol} / \mathrm{L}$ sodium phosphate buffer (pH 6.6) and $1 \mathrm{~mL}$ of $1 \%$ potassium ferricyanide (freshly prepared). Total preparation was incubated in a water bath at $50^{\circ} \mathrm{C}$ for $20 \mathrm{~min}$. After incubation, 2.5 $\mathrm{mL}$ of $10 \%$ trichloroacetic acid was added to the mixture and then centrifuged at $3000 \mathrm{r} / \mathrm{min}$ for $10 \mathrm{~min}$.

The supernatant $(2.5 \mathrm{~mL})$ was mixed with $2.5 \mathrm{~mL}$ of distilled water and $2.5 \mathrm{~mL}$ of freshly prepared $0.1 \%$ $\mathrm{FeCl}_{3}$ and left to stand at room temperature for $10 \mathrm{~min}$. The absorbance of the reaction mixture was measured at $700 \mathrm{~nm}$ against the blank using a spectrophotometer. The higher absorbance of the reaction mixture indicates greater reducing power. BHT was used as a positive control at the same selected concentrations and in the same operating conditions as the samples. The sample concentration at the absorbance of 0.5 was used for comparison of the ferric reducing power of the sample. $\mathrm{IC}_{50}$ value $(\mu \mathrm{g} / \mathrm{mL})$ is the effective concentration giving an absorbance of 0.5 for reducing power and was obtained from the linear regression analysis. All analysis was run in triplicate and averaged.

\subsection{Allelopathic activity}

The volatile oil of $P$. odora roots, as well as its major compounds $\underline{\mathbf{1}}$ and $\underline{\mathbf{2}}$ were tested for allelopathic activity on two test plants: Medicago sativa and Medicago s. falcata.
The seeds of Medicago species were procured from Vita Maroc Company, a development partner of Moroccan agriculture. These tested plants were chosen because of their high percentage of germination. Also, they have a small seed that is quite easy to handle in a laboratory experiment. To evaluate the allelopathic potential of $P$. odora EO, various concentrations $(7.81,15.62,31.25,62.5,125,250$, and $500 \mu \mathrm{g} / \mathrm{mL}$ ) were prepared using an aqueous solution of Tween-20 at $0.25 \%(\mathrm{v} / \mathrm{v})$ as surfactant and control treatment. EO has low solubility in distilled water. $4 \mathrm{ml}$ of each concentration was added in the sterilized Petri dish $(9 \mathrm{~cm})$ contained two layers of filter paper (Whatman $\mathrm{N}^{\circ} .1$ ) as well as 25 seeds of the tested plants (M. sativa and M. s. falcata). The dishes were sealed hermetically and incubated in the growth chamber for 7 days in the dark at $25^{\circ} \mathrm{C}$. Distilled water and Tween-20 in distilled water were served as controls. The experiments were repeated in 3 replicates. A few morphological characteristics, such as germination percentage, radicle length, and hypocotyl length, were determined. The inhibitory effect was appraised by counting the number of daily germinated seeds until the control stabilized, reaching the maximum germination. The emergence of a radical approximately $1 \mathrm{~mm}$ was taken as the index of germination ${ }^{14,15}$. After 7 days, the number of seeds that germinated was counted and their radicle length and hypocotyl length were determined. The following formula calculated the final germination percentage:

Germination percentage $=$ Number of germinated seeds x 100/Total number of seeds.

Compounds $\underline{\mathbf{1}}$ and $\underline{\mathbf{2}}$ were dissolved in $0.5 \mathrm{~mL}$ diethyl ether, and test solutions were produced at the same final concentrations as the EO $(7.81,15.62,31.25$, $62.5,125,250$ and $500 \mu \mathrm{g} / \mathrm{mL}$ ). The tested seeds were wetted with $0.5 \mathrm{~mL}$ diethyl ether as a control group. Distilled water and diethyl ether $(0.5 \mathrm{~mL})$ in distilled water were served as controls. Experiments were repeated in 3 replicates.

\subsection{Statistical analysis}

All data obtained were subjected to a one-way analysis of variance (ANOVA) test using a statistical package program (SPSS version 23.0), and the significance of the difference between the means was followed by the Tukey test, using ( $p<0.05$ and $\mathrm{p}<0.01)$ as the level of importance. Correlations among data obtained were calculated using Pearson's correlation coefficient. Data were expressed with mean \pm standard error of three parallel measurements.

\section{Results and discussion}

\subsection{GC analysis and isolation of the major components of $P$. odora EO}

Hydro-distillation of $P$. odora roots produced a yellow oil with a mean yield of $0.9 \%$. GC analysis of the EO indicated the presence of 75 volatile compounds. Among them, two accounted for $89.96 \%$ of the oil (Figure 1). 


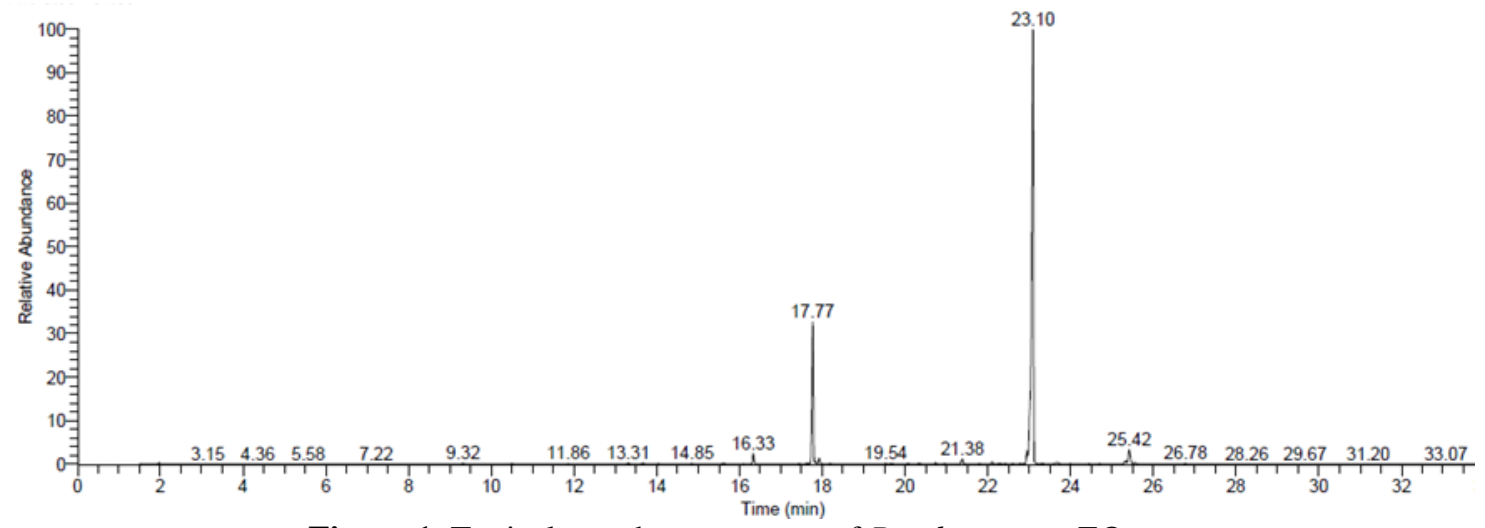

Figure 1. Typical gas chromatogram of $P$. odora roots EO

The EO was then subjected to column chromatography over silica gel using a gradient of n-hexane and diethyl ether as eluents to give know compounds $\underline{\mathbf{1}}$ and $\underline{\mathbf{2}}$ with a yield of $56.14 \%$ and $18.18 \%$ respectively.

The analysis of ${ }^{1} \mathrm{H}$ NMR and ${ }^{13} \mathrm{C}$ NMR spectral data gave the total ${ }^{1} \mathrm{H}$ and ${ }^{13} \mathrm{C}$ assignments for these compounds.

The identification of compounds $\underline{\mathbf{1}}$ and $\underline{\mathbf{2}}$ (Figure 2) was confirmed by comparison of their spectral data in ${ }^{1} \mathrm{H}$ NMR and ${ }^{13} \mathrm{C}$ NMR with those previously reported by Ezoubeiri ${ }^{2}$. The identity of the two peaks observed at $17.77 \mathrm{mn}$ and $23.10 \mathrm{mn}$ was confirmed by GC analysis under the same conditions of the two isolated compounds $\underline{\mathbf{2}}$ and $\underline{\mathbf{1}}$, respectively.

Compound 1: Isobutyric acid 2-isopropyl-4-methylphenylester $\left(\mathrm{C}_{14} \mathrm{H}_{20} \mathrm{O}_{2}\right)$, yellow oil; represents $72.37 \%$ of the EO;<smiles>Cc1ccc(OC(=O)C(C)C)c(C(C)C)c1</smiles>
1
${ }^{1} \mathrm{H}-\mathrm{NMR}\left(300.13 \mathrm{MHz}, \mathrm{CDCl}_{3}, \delta / \mathrm{ppm}, \mathrm{J} / \mathrm{Hz}\right): 6.92$ $(1 \mathrm{H}, \mathrm{d}, \mathrm{J}=9, \mathrm{H}-5), 7.09$ (1H, d, J=9, H-6), 7.17(1H, s, H-3), $1.28\left(6 \mathrm{H}, \mathrm{d}, \mathrm{J}=6.6, \mathrm{H}-2^{\prime}, \mathrm{H}-3\right.$ ') $1.40(6 \mathrm{H}, \mathrm{d}$, $\mathrm{J}=6.6, \mathrm{H}-3$ ”, H-4”), $2.36\left(3 \mathrm{H}, \mathrm{s}, \mathrm{CH}_{3}\right), 2.91(1 \mathrm{H}, \mathrm{m}$, $\mathrm{J}=6.6, \mathrm{H}-2$ '”), 3.06(1H, m, J=6.6, H-1').

${ }^{13} \mathrm{C}-\mathrm{NMR}\left(300.13 \mathrm{MHz}, \mathrm{CDCl}_{3}, \delta / \mathrm{ppm}\right): 19.09$ (C-3", C-4”), $21.15\left(\mathrm{CH}_{3}\right), 22.9$ (C2', C3'), 27.34 (C1'), 34.37 (C2"), 121.98 (C6), 127.18 (C5), 127.24(C3), 135.60(C4), 139.78 (C2), 145.93 (C1), 175.70 (C1").

Compound 2: 2-Isopropyl-4-methylphenol $\left(\mathrm{C}_{10} \mathrm{H}_{14} \mathrm{O}\right)$, yellow oil; represents $17.59 \%$ of the EO; ${ }^{1} \mathrm{H}$ - NMR (300.13 MHz, $\left.\mathrm{CDCl}_{3}, \delta / \mathrm{ppm}, \mathrm{J} / \mathrm{Hz}\right): 6.91$ $(1 \mathrm{H}, \mathrm{dd}, \mathrm{J}=8.1 ; \mathrm{J}=2.1, \mathrm{H}-5), 6.70(1 \mathrm{H}, \mathrm{d}, \mathrm{J}=8.1, \mathrm{H}-6)$, $7.07(1 \mathrm{H}, \mathrm{d}, \mathrm{J}=2.1, \mathrm{H}-3), 1.31(6 \mathrm{H}, \mathrm{d}, \mathrm{J}=6.9, \mathrm{H}-2$ ', H-C3'), $2.34\left(3 \mathrm{H}, \mathrm{s}, \mathrm{CH}_{3}\right), 3.27\left(1 \mathrm{H}, \mathrm{J}=6.9, \mathrm{H}-1^{\prime}\right)$, $5.35(1 \mathrm{H}, \mathrm{s}, \mathrm{OH})$.

${ }^{13} \mathrm{C}-\mathrm{NMR}\left(300.13 \mathrm{MHz}, \mathrm{CDCl}_{3}, \delta / \mathrm{ppm}\right): 20.76\left(\mathrm{CH}_{3}\right)$, 22.68 (C2', C3'), 26.95 (C1'), 115.2 (C6), 126.98 (C3-C5), 129.90 (C4), 134.35 (C2), 150.61 (C1).<smiles>Cc1ccc(O)c(C(C)C)c1</smiles>

Figure 2. Chemical structures of compounds $\underline{\mathbf{1}}$ (isobutyric acid 2-isopropyl-4-methyl-phenylester) and $\underline{\mathbf{2}}$ (2isopropyl-4-methylphenol) isolated from $\mathrm{EO}$ of $P$. odora

\subsection{Total phenolic content and antioxidant activities}

The phenolic content of $P$. odora $\mathrm{EO}$ was calculated to be $78.25 \pm 0.26 \mathrm{mg}$ EAG/g DW (dry weight). It is higher than that of $P$. inuloides EO $(55.4 \pm 0.1 \mathrm{mg}$ EAG/g DW) ${ }^{16}$. According to Pietta ${ }^{17}$ and Wojdylo ${ }^{18}$, there is a strong relationship between phenolic content and antioxidant activity, as the phenols possess strong scavenging ability for free radicals due to their hydroxyl groups. Therefore, the phenolic content of plants may directly contribute to their antioxidant propriety.

Thus, the coefficient of correlation between phenolic content and antioxidant activity was studied in this work using Pearson's method. The obtained results showed a high negative correlation coefficient between $\mathrm{IC}_{50}$ values for DPPH/ FRAP/ $\mathrm{H}_{2} \mathrm{O}_{2}$ essays and phenolic content of EO $(r=-0.995, r=-0.997$ and $r=-0.993$, respectively).

In this study, the antioxidant activity of $P$. odora EO, and its major compounds $\underline{\mathbf{1}}$ and $\underline{\mathbf{2}}$ were measured using three different tests, namely DPPH assay, hydrogen peroxide $\left(\mathrm{H}_{2} \mathrm{O}_{2}\right)$ scavenging assay and ferric reducing power assay (FRAP).

The $\%$ inhibition (or absorbance) of both standards and samples was calculated for each concentration and the graphs were plotted (\% inhibition or absorbance against concentration). From these graphs, $\mathrm{IC}_{50}$ values $\left(\mathrm{IC}_{50}\right.$ represents the concentration of a sample that is required for $50 \%$ inhibition in vitro) 
were calculated for standards and samples of $P$. odora. A lower $\mathrm{IC}_{50}$ value indicates a higher antioxidant activity.

As seen in Table 1, the EO of P. odora and its main phenolic component $\underline{\mathbf{2}}$ showed strong DPPH radical scavenging activity, hydrogen peroxide scavenging activity and ferric reducing power. The rank order of antioxidant potency was the same for the three assays, namely, in decreasing order, compound $\underline{\mathbf{2}}$, followed by EO and compound $\underline{\mathbf{1}}$.

DPPH radical scavenging activity: the effectiveness of the EO and its major phenolic compound $\underline{\mathbf{2}}$ to scavenge DPPH radical was no significant different ( $>0.05)$ (Table 1). However, significant differences $(\mathrm{p}<0.05)$ were found between EO, compound $\underline{\mathbf{1}}$, and BHT. The antiradical activities of EO and compound $\underline{\mathbf{2}}$ with $\mathrm{IC}_{50}$ values of $21.60 \mu \mathrm{g} / \mathrm{mL}$ and $21.12 \mu \mathrm{g} / \mathrm{mL}$ respectively, were better than those of the compound $\underline{\mathbf{1}}(49.78 \mu \mathrm{g} / \mathrm{mL})$ and BHT $(36.10 \mu \mathrm{g} / \mathrm{mL})(\mathrm{p}<0.05)$.
Reducing power activity: There was no significant difference $(p>0.05)$ between EO and its major phenolic compound $\underline{\mathbf{2}}$. The $\mathrm{IC}_{50}$ values of $\mathrm{EO}$ and $\underline{\mathbf{2}}$ were comparable and showed strong activity (16.39 $\mu \mathrm{g} / \mathrm{mL}$ and $15,65 \mu \mathrm{g} / \mathrm{mL}$, respectively) $(\mathrm{p}<0.05)$. Indeed, these $\mathrm{IC}_{50}$ values were less than that of the natural standard antioxidant. Compound $\underline{\mathbf{1}}$ had a higher $\mathrm{IC}_{50}$ value $(225.11 \mu \mathrm{g} / \mathrm{mL})$, which indicated its weak, reducing ability.

Hydrogen peroxide scavenging assay: statistical analysis showed significant differences $(\mathrm{p}<0.05)$ were found between $\mathrm{EO}$, compound $\underline{\mathbf{1}}, \underline{\mathbf{2}}$, and ascorbic acid. The phenolic compound $\underline{\mathbf{2}}\left(\mathrm{IC}_{50}\right.$ value of $\left.6.51 \mu \mathrm{g} / \mathrm{mL}\right)$ exhibited the highest antioxidant activity (Table 1) followed by EO $(22.90 \mu \mathrm{g} / \mathrm{mL})$, whereas the lower one was observed for compound $\underline{\mathbf{1}}$. The effectiveness of $\underline{\mathbf{2}}\left(\mathrm{IC}_{50}=6.51 \mu \mathrm{g} / \mathrm{mL}\right)$ was significantly $(\mathrm{p}<0.05)$ higher than that of natural antioxidant standard $\left(\mathrm{IC}_{50}=10.34 \mu \mathrm{g} / \mathrm{mL}\right)$.

Table 1. Antioxidant activity of essential oil (EO) of P. odora and its main components $\underline{1}$ and $\underline{2}$ in terms of $\mathrm{IC}_{50}$ $(\mu \mathrm{g} / \mathrm{mL})$ values with $\mathrm{p}<0.05$.

\begin{tabular}{|c|c|c|c|}
\hline Samples & DPPH & FRAP & $\mathrm{H}_{2} \mathrm{O}_{2}$ \\
\hline EO & $21.60 \pm 0.21$ & $16.39 \pm 0.15$ & $22.90 \pm 0.12$ \\
\hline$\underline{\mathbf{1}}$ & $49.78 \pm 0.16$ & $225.11 \pm 0.45$ & $68.30 \pm 0.28$ \\
\hline$\underline{\mathbf{2}}$ & $21.12 \pm 0.06$ & $15.65 \pm 0.13$ & $6.51 \pm 0.05$ \\
\hline BHT & $36.10 \pm 0.03$ & - & - \\
\hline Ascorbic acid & - & $120.03 \pm 0.25$ & $10.34 \pm 0.11$ \\
\hline
\end{tabular}

The phenolic compound $\underline{\mathbf{2}}$ was found to be more effective than the natural standard (ascorbic acid) and the synthetic standard (BHT). The finding that the results of the DPPH and FRAP assays for plant extracts were highly correlated agreeing to the work of others, and is consistent with the view that the two methods share a similar mechanistic basis, which was a transfer of electrons from the antioxidant to reduce an oxidant ${ }^{19}$.

So far, no antioxidant activity of $P$. odora EO has been reported; therefore, no comparison is possible with the same species. However, there are few reports on the antioxidant properties of the oils from the other plants belonging to the same genus.

Hussein ${ }^{4}$ studied the antiradical capacity of aerial parts of $P$. jaubertii from Yemen; they found that volatile oils of this species showed high radical scavenging activity as revealed by its ability to reduce violet DPPH radicals form. Its antiradical capacity was well comparable to that of ascorbic acid, which is known for its use as a natural antioxidant. AL-Hajj ${ }^{16}$ reported that EO from $P$. inuloides roots demonstrated lower antioxidant activity in the DPPH assay when compared to gallic acid used as a standard natural antioxidant; the $\mathrm{IC}_{50}$ value of $P$. inuloides was calculated to be $31.18 \mu \mathrm{g} / \mathrm{mL}$. Shariatifar ${ }^{20}$ evaluated the antioxidant activity of Iranian $P$. gnaphalodes EO in soybean oil during the storage period. According to their results in DPPH assay, EO was less effective than synthetic antioxidant (BHT). The antiradical ability of EO from the aerial parts of $P$. arabica grown in Algeria was examined by Djermane ${ }^{21}$. Results revealed that the percent inhibition of free radical DPPH for the EO is deficient, almost zero compared to that of ascorbic acid at all used concentrations. These authors report that the low antioxidant activity of the EO of $P$. arabica can be explained by its weak chemical profile of compounds known for their antioxidant potential, such as phenolic compounds. Many previous studies reported that the antioxidant capacity of plant extracts could be attributed to the total phenolic content ${ }^{9,22-24}$. Hanbali et al. ${ }^{3}$ reported the presence in the EO of Moroccan P. odora roots of other phenolic constituents such as carvacrol and cresol $(2.78 \%$ and $0.03 \%$ of total oil, respectively). On the other hand, Zefzoufi ${ }^{9}$ reported that methanol, ethyl acetate, and butanol extracts of $P$. odora exert a powerful antiradical effect (DPPH essay). Their radical scavenging activities with $\mathrm{IC}_{50}$ values of $4 \mu \mathrm{g} / \mathrm{mL}, 5 \mu \mathrm{g} / \mathrm{mL}$ and $4 \mu \mathrm{g} / \mathrm{mL}$, respectively, thus were better than that of $P$. odora EO $(21.60 \mu \mathrm{g} / \mathrm{mL})$ and the phenolic compound $\underline{\mathbf{2}}(21.12 \mu \mathrm{g} / \mathrm{mL})$.

Thus, in the present study, the high antioxidant activity of $\underline{\boldsymbol{2}}$ is possibly related to its chemical 
structure as a phenol derivative. This may also explain the reduced capacity of compound $\underline{\mathbf{1}}$. As a result of the literature, the antioxidant properties of EOs are related to their content of phenolic compounds and terpenes with conjugated double bonds, which act as donors of hydrogen or/ and electron, and to their different concentration level in these essential oils ${ }^{25}$. Thus, all volatile compounds identified in EO of $P$. odora by Hanbali et al. ${ }^{3}$ might be contributing to the potent antioxidant ability of this EO.

Our results revealed a good relationship between the antioxidant activity of the EO and that of the phenolic constituent $\underline{\mathbf{2}}$. Interestingly, this phenolic component has been shown to have antimicrobial activity Ezoubeiri ${ }^{2}$, while compound $\underline{\mathbf{1}}$ was inactive for all tested strains. Consequently, the antioxidant activity of the EO of $P$. odora could be related in large part to the presence of this phenolic component in high quantity $(17.59 \%)$. To conclude, we can say that our results show a vital antioxidant capacity of the EO of $P$. odora from Morocco, which was well comparable in DPPH/Reducing power essays to that of its main phenolic constituent $\underline{\mathbf{2}}$ (2-isopropyl-4-methylphenol).
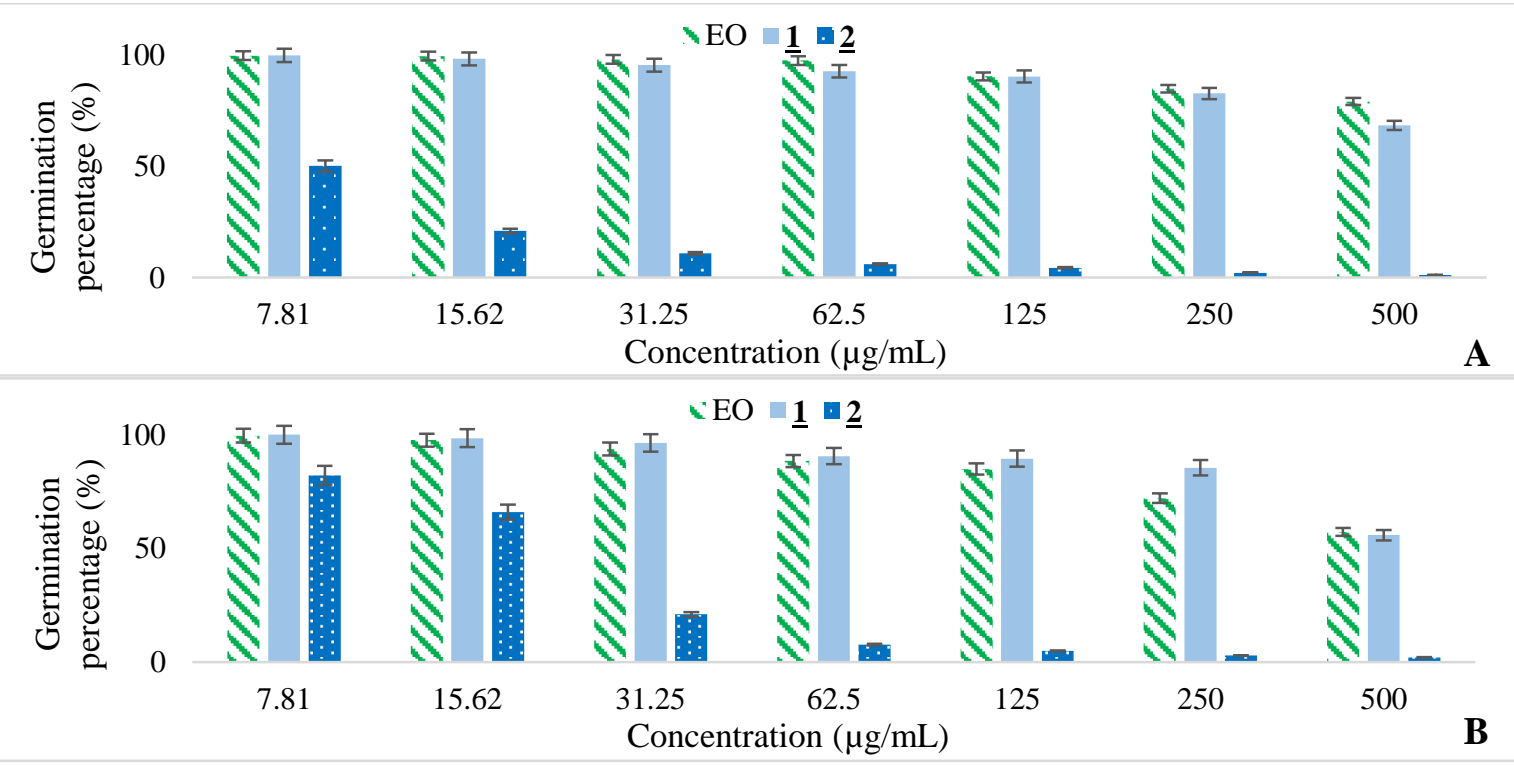

Figure 3. Allelopathic effect of EO and compounds $\underline{\mathbf{1}}$ and $\underline{\mathbf{2}}$ from $P$. odora on germination percentage of Medicago sativa (A) and Medicago s. falcata (B) at different concentrations

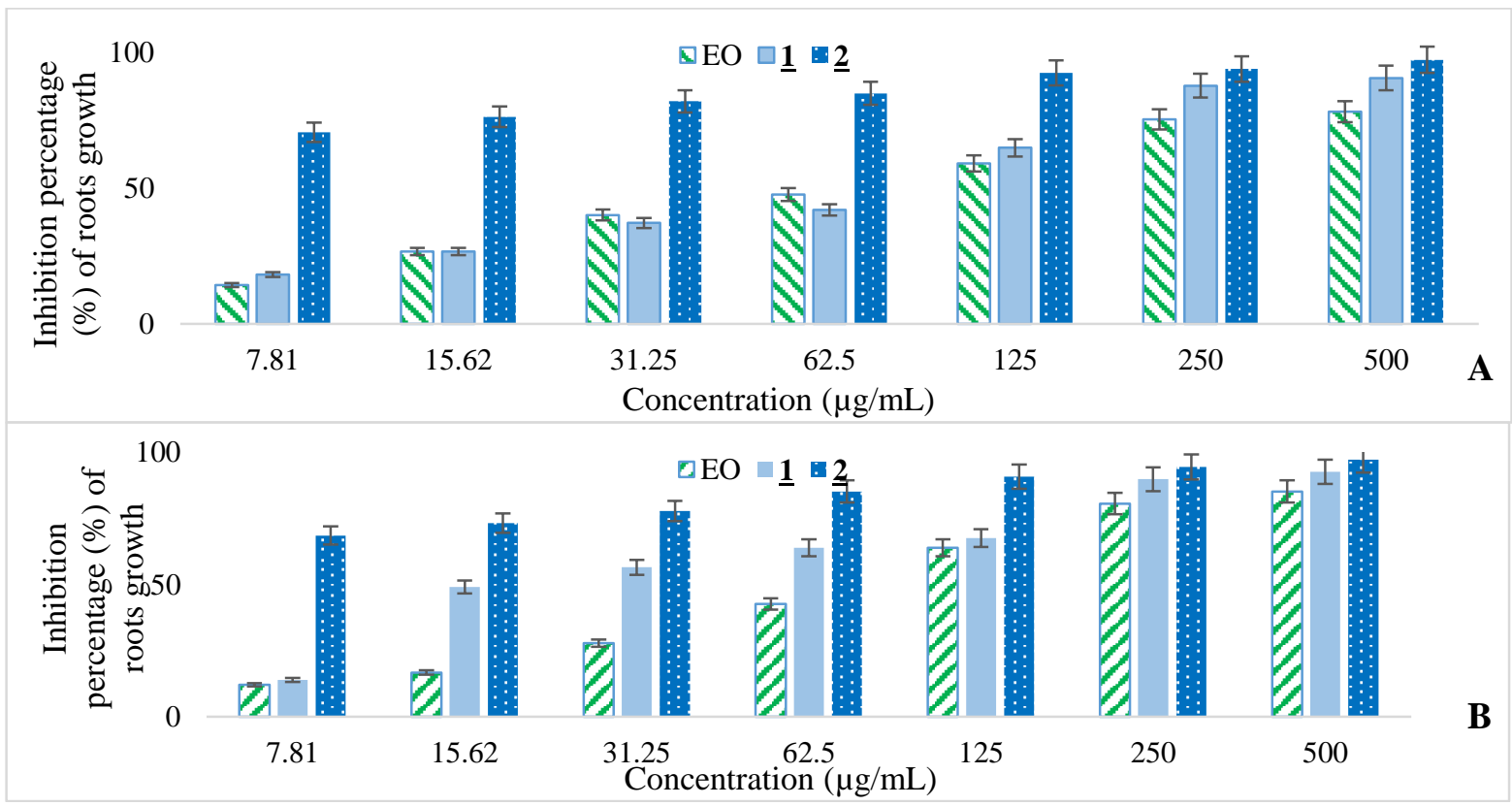

Figure 4. Allelopathic effect of EO and compounds $\underline{\mathbf{1}}$ and $\underline{\mathbf{2}}$ from $P$. odora on roots growth of Medicago sativa (A) and Medicago s. falcata (B) at different concentrations 


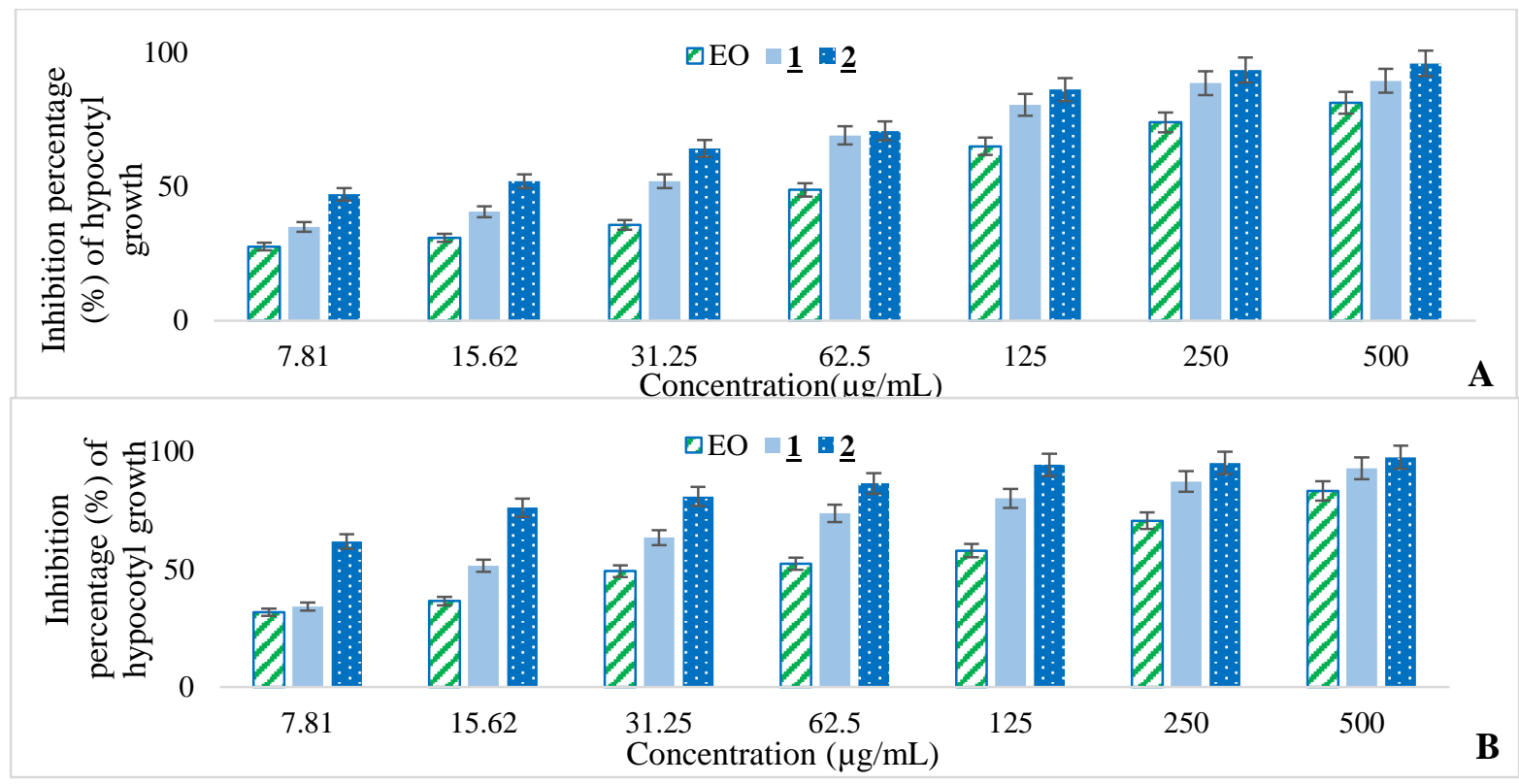

Figure 5. Allelopathic effect of EO and compounds $\underline{\mathbf{1}}$ and $\underline{\mathbf{2}}$ from $P$. odora on hypocotyls growth of Medicago sativa (A) and Medicago s. falcata (B) at different concentrations

\subsection{Allelopathic potential}

In this study, the EO of Moroccan P. odora and its major isolated constituents $\underline{\mathbf{1}}$ and $\underline{\mathbf{2}}$ were also investigated for the first time for their allelopathic activities at various concentrations. Two Moroccan forage plants were used as test plants: $M$. sativa and M. s. falcata. The allelopathic potential of the EO and its main components $\underline{\mathbf{1}}$ and $\underline{\mathbf{2}}$ against $M$. sativa and $M$. falcata was illustrated in Figures 3-5.

Data depicted in Figure 3 showed that EO, compounds $\underline{\mathbf{1}}$ and $\mathbf{2}$ inhibited seed germination of both tested plants; a dose-response relationship was found in seeds germination inhibition of the two tested plants; the inhibition effect increased with an increase in the concentration of the chemical samples. At 7.81 $\mu \mathrm{g} / \mathrm{mL}$, it was found that only $\underline{\mathbf{2}}$, inhibited seed germination of M. sativa and M. falcata by $49.73 \%$ and $17.83 \%$, respectively. The EO and compound $\underline{\mathbf{1}}$ showed no significant effect ( $p>0.05$ ).

The EO and compound $\underline{\mathbf{1}}$ did not affect the germination a lot (Figure 3). Generally, the germination of the two types of seeds was less sensitive to these two samples. For example, at a dose of $250 \mu \mathrm{g} / \mathrm{mL}$, EO and compound $\mathbf{1}$ inhibited M. falcata by $27.90 \%$ and $14.54 \%$ while M. sativa was affected by $14.97 \%$ and $17.14 \%$, respectively.

At the highest dose tested $(500 \mu \mathrm{g} / \mathrm{mL})$, phenolic compound $\underline{\mathbf{2}}$ exhibited the highest inhibitory allelopathic effect on tested plants, 98.8\% and $97.97 \%$, almost $100 \%$. While EO and compound $\mathbf{1}$ inhibited seed germination of $M$. sativa by $20.8 \%$ and $31.6 \%$, respectively, which is lower than values showed for M. falcata ( $42.8 \%$ et $44.2 \%$, respectively), at $500 \mu \mathrm{g} / \mathrm{mL}$. Overall, results showed that EO and compound 1 were more active on seed germination inhibition of $M$. falcata than that of $M$. sativa. In contrast, compound $\underline{\mathbf{2}}$ inhibited significantly $(\mathrm{p}<0.05)$ seed germination of M. sativa more than M. falcata at all tested concentrations.

In terms of seedling growth, results (Figures 4-5) showed that at $500 \mu \mathrm{g} / \mathrm{mL}$ concentration of $P$. odora samples, the inhibitory effect on the tested plants was maximum compared to that at $7.81 \mu \mathrm{g} / \mathrm{mL}$ concentration. Indeed, inhibition activity on seedling growth parameters (radical and hypocotyl length) significantly $(\mathrm{p}<0.05)$ increased gradually with the increase in the concentrations of $P$. odora samples. Overall, the best inhibitory activity in root and hypocotyl length on M. sativa and M. falcata was observed for phenolic constituent $\underline{\mathbf{2}}$ at all concentrations.

For root elongation (Figure 4), at low concentration $(7.81 \mu \mathrm{g} / \mathrm{mL})$, phenolic compound $\underline{\mathbf{2}}$ showed high percentages of inhibition on M. sativa and M. falcata, $70.50 \%$ and $68.52 \%$, respectively. In contrast, both $\mathrm{EO}$ and compound $\underline{1}$ showed a low level of inhibition on M. sativa $(14.30 \%$ and $18.10 \%)$ and M. falcata $(12.04 \%$ and $13.89 \%)$. The inhibitory effect of phenolic compound $\underline{\mathbf{2}}$, on the two forage plants, was better than that observed for the EO or compound 1 at all the concentrations. Also, the results indicate that compound $\underline{\mathbf{1}}$, was more effective than EO in root length inhibition on $M$. falcata at concentrations ranging from $15.62 \mu \mathrm{g} / \mathrm{mL}$ to $500 \mu \mathrm{g} / \mathrm{mL}$. In the case of $M$. sativa, compound $\underline{\mathbf{1}}$, when compared to EO showed high percentages in root development inhibition at concentrations ranging from $125 \mu \mathrm{g} / \mathrm{mL}$ to $500 \mu \mathrm{g} / \mathrm{mL}$.

In the matter of hypocotyl length, results (Figure 5) showed that the three samples tested were more active on the hypocotyl growth of M. falcata than M. sativa.

Compound $\mathbf{2}$ still was the most effective on the tested plants, while the EO showed the lowest inhibition 
percentages in the growth of hypocotyl at all concentrations.

Looking at all the effects of these tested natural samples, phenolic component $\underline{\mathbf{2}}$ exhibited significantly $(\mathrm{p}<0.05)$ the highest phytotoxicity on M. sativa and M. falcata. Compound $\mathbf{1}$ and EO have moderate phytotoxic effects on the seed germination of the two seeds essayed when compared to compound $\underline{\mathbf{2}}$. In terms of seedling growth, EO and compound $\underline{1}$ at high concentrations (250 and $500 \mu \mathrm{g} / \mathrm{mL}$ ) reduced radicles and hypocotyls length by strong percentages.

Compound $\underline{\mathbf{2}}$ was more active on the root growth of both plants than on seed germination. However, the seed germination of $M$. falcata was less sensitive to inhibition by $\underline{\mathbf{2}}$ than $M$. sativa. In the matter of radicle and hypocotyl elongation, compound $\underline{\mathbf{2}}$ affected both tested plants, in a similar way. Moreover, roots seemed to be more sensitive to the phytotoxic activity of phenolic compound $\underline{\mathbf{2}}$ than hypocotyls. Our result endorses earlier studies which reported that hypocotyl growth is less sensitive to allelochemicals than root growth ${ }^{26-28}$. The most sensitivity of roots was probably because the roots were in direct contact with the extract.

Similarly, the seedling growth was more sensitive to the phytotoxic activity of the volatile oil and compound 1 than seed germination: the process of germination was active while the EO and compound 1 probably affected the elongation process. Our results seem in agreement with those obtained by De Martino ${ }^{26}$. Also, according to Azirak ${ }^{29}$, seeds that germinated in the presence of essential oils usually did not develop normally.

Overall, our results revealed that the EO and its two main components $\underline{\mathbf{1}}$ and $\underline{\mathbf{2}}$ showed an excellent allelopathic effect against the two forage species at concentrations of $7.81-500 \mu \mathrm{g} / \mathrm{mL}$ in terms of seed germination, root length and hypocotyl growth. These findings were in agreement with those of earlier studies wherein volatile oils emanating from diverse aromatic plants, as well as their components, were reported to possess a phytotoxic effect against a wide range of weeds and crops species 26,30-35.

Based on previous work ${ }^{36,37}$, and in agreement with our research, several essential oils or their compounds showed different inhibitory effects against plants, which were dose-dependent and also speciesdependent. Treated plant seeds revealed differences in their responses towards the studied $P$. odora samples.

Previous research on the phytotoxic activity of more than 70 monoterpenes in the vapor phase ${ }^{38}$ and/or in a petri dish contact experiment ${ }^{39,40}$ showed that monoterpene alcohols and ketones were the most active, followed by aldehydes, ethers, and phenols. Acetates of monoterpene alcohols and hydrocarbons were the least phytotoxic. Also, De Martino 26 reported that carvacrol, thymol, $p$-cymene, and 1,8-cineole inhibited the seedling growth of the seeds, but they did not affect their germination.

Similarly, Azirak ${ }^{29}$ has assessed the inhibition of six weed seeds germination by carvacrol, thymol, carvone, and limonene at four different concentrations $(500,250,125$, and $62.5 \mu \mathrm{g} / \mathrm{ml})$. Results revealed that limonene was a less toxic compound on weed species, while carvacrol gave a lower germination rate among the four components. Obtained results also indicated that only Alcea pallida showed resistance to all components.

Similar results were found in the present study; the inhibitory effects of $\underline{\mathbf{1}}$ on seed germination and seedling growth of two plant species tested were lower than those of $\underline{\mathbf{2}}$.

Compound $\underline{\mathbf{2}}$ is one carvacrol/thymol isomer. The highest phytotoxic potential of compound $\underline{\mathbf{2}}$ is possibly related to its chemical structure as a phenol derivative. This may also explain the low inhibitory effect of compound $\mathbf{1}$. According to Kordali ${ }^{39}$, alcohol derivatives of oxygenated monoterpenes were more phytotoxic than their acetate derivatives, and this can be attributed to the high solubility in water of alcohols that are polar compounds as compared with acetates.

Angelini ${ }^{33}$ and Azirak ${ }^{29}$, report that the phytotoxic potential of different essential oils was attributed to their main constituent especially oxygenated monoterpenes. Oxygenated monoterpenes, mainly alcohols, and ketones have been classified by other authors as indicators of the herbicidal activities of essential oils ${ }^{41-43}$. Also, Rolli ${ }^{44}$ revealed that higher contents of monoterpene alcohols, aldehydes, and phenylpropanoids in an EO might be predictors of higher inhibitory effect.

In our case, EO showed the lowest phytotoxic activity on the tested seeds. EO of $P$. odora contained isobutyric acid 2-isopropyl-4-methyl-phenylester (1) and 2-isopropyl-4-methylphenol (ㅁ) as major components $(72.37 \%$ and $17.59 \%$ respectively).

Previous research on $P$. odora EO showed the occurrence of other oxygenated monoterpenes such as carvacrol, 1,8-cineole, linalool, camphor, and $\alpha$-terpineol, as minor oxygenated monoterpenes ${ }^{3}$. Many plant essential oils rich in carvacrol and/or thymol have been reported to possess high herbicidal effects against the germination and seedling growth of weeds and cultivated crops ${ }^{30}$. De Martino ${ }^{26}$ reported that carvacrol, thymol, $p$-cymene, and 1,8-cineole inhibited the seedling growth of the seeds, but they did not affect their germination.

In the same way, other authors ${ }^{39,45}$ previously reported that 1,8-cineole and camphor have strong phytotoxic effects against various plant species. At the same time, linalool ${ }^{46,47}$, and $\alpha$-pinene ${ }^{45-47}$ are known as high inhibitors of seed germination and seedling growth. 
Therefore, our EO, to a certain extent, supported the above rule probably because its second main constituent is one thymol isomer, which was previously reported as being highly effective against the germination of different weed and crop seeds ${ }^{26-29}$. However, in our research, the phytotoxic effect of the EO was lower than that of its two major compounds, namely $\underline{\mathbf{1}}$ and $\underline{\mathbf{2}}$.

According to Synowiec ${ }^{36}$, both the major and minor constituents, as well as their proportions, play an important role in the final phytotoxicity of an EO.

In the case of bioactivity of EOs, many authors agree that although the major components are vital for their biological activity, the minor components also play a significant role because of their additive and synergistic effects. The same authors reported that antagonistic effects have also been observed ${ }^{24,48}$. From our viewpoint, this is the same in the case of the phytotoxic activity of EO of P. odora. Its low phytotoxic activity is probably related to antagonistic effects of its chemical constituents. In fact, in the case of complex mixtures such as essential oils, the final inhibitory effect may result from the interactions (synergistic or antagonistic) of particular compounds ${ }^{49}$. Thus, as proved by Vokou ${ }^{49}$, monoterpenoids tested in pairs on seed germination can act independently or show both synergistic and antagonistic effects.

\section{Conclusion}

To the best of our knowledge, this is the first report on antioxidant and allelopathic effects of $P$. odora roots EO (and/or its two major components). The presented data show that the EO and its main compounds possess an antioxidant activity. Following the results obtained by reducing power, $\mathrm{H}_{2} \mathrm{O}_{2}$ and DPPH methods, the highest antioxidant properties are exhibited by 2-isopropyl-4methylphenol followed by EO, whereas the lowest activity has been seen in isobutyric acid 2-isopropyl-4-methyl-phenylester. The antioxidant activity of 2-isopropyl-4-methylphenol, which was well comparable in DPPH / Reducing power assays to that of EO, was found to be better than those of the natural standard (ascorbic acid) and the synthetic standard (BHT). Therefore, our results confirm the potential use in the food industry of EO of $P$. odora roots as a food flavor, natural antioxidant and a preventive agent for many diseases caused by free radicals. Indeed, for organoleptic, technical and microbiological reasons, the use of the essential oils as food additives improve clearly the sensory and health quality of foods, enhance their antioxidant stability and prolong their shelf-life. On the other hand, our results provide plausible evidence that $P$. odora as a medicinal and aromatic plant is potentially promising resource of "eco-friendly" bio-herbicide. While the least phytotoxic was the EO and /or isobutyric acid 2-isopropyl-4- methyl-phenylester, the second isolated compound from this EO inhibited strongly the seed germination and seedling growth of two forage plants Medicago sativa and Medicago falcata. Thus, it was proved that in the case of complex mixtures such as EOs, the final phytotoxic effect may result from both synergistic and antagonistic interactions of its particular compounds. In our experiment, we also proved that the inhibitory effect of an EO (or its particular compounds) depends not only on the tested doses, but also on the tested plants.

\section{Acknowledgments}

The authors gratefully acknowledge the CUR CA2D of Chouaib Doukkali University (El JadidaMorocco) for its support.

\section{References}

1- L.L. Liu, J.L. Yang, Y.P. Shi, Phytochemicals and Biological Activities of Pulicaria Species, Chem. Biodivers., 2010, 7, 327-349.

2- A. Ezoubeiri, C.A. Gadhi, N. Fdil, A. Benharref, M. Jana, M. Vanhaelen, Isolation, and antimicrobial activity of two phenolic compounds from Pulicaria odora L, J. Ethnopharmacol., 2005, 99, 287-292.

3- F.E. Hanbali, M. Akssira, A. Ezoubeiri, C.E. Gadhi, F. Mellouki, A. Benherraf, A.M. Blazquez, H. Boira, Chemical composition and antibacterial activity of essential oil of Pulicaria odora L, J. Ethnopharmacol., 2005, 99, 399-401.

4- S.R. Hussein, M.M. Marzouk, M.M. Soltan, M.M. Ahmed, M.M. Said, A.R. Hamed,

Antioxidant protective effects and chemosystematic significances, J. Food. Drug. Anal., 2017, 3, 333-339.

5- M.N. Algabr, R. Mekkiou, S. Ameddah, A. Menad, O. Boumaza, R. Seghiri, S. Benayache, F. Benayache, Antioxydant activities from the aerial parts of Pulicaria jaubertii, J. Adv. in Nat. App. Sci., 2010, 4, 63-70.

6- M. Gherib, B. Chahrazed, I.A. El-haci, T.M. Chaouche, F. Bekkara, Antioxidant and antibacterial activities of aerial part essential oil and some organic extracts from the Algerian medicinal plant Pulicaria mauritanica coss, Int. J. Pharm. Sci. Res., 2016, 7, 76-84.

7- A. Hamdouch, A. Asdadi, F. Achemchem, B. Chebli, M. El Hadek, L.M. Idrissi-Hassani, Phytochemical analysis, Antifungal, antibacterial and antioxidant properties of Pulicaria mauritanica from south-east of Morocco, J. Mater. Env. Sci., 2018, 9, 1762-1770.

8- N. Touati, K. Saidani, H. Boudries, H. Hammiche, N. Ouazene, F. Bedjou, Antibacterial activity of phenolic compounds of Pulicaria odora, wild plant in northern Algeria, Inter. Food. Res. J., 2018, 25, 2121-2130.

9- M. Zefzoufi, M. Chatir, R. Fdil, H. Bouamama, 
A. Mouzdahir, K. Sraidi, A. Abouzaid, Antioxydant capacity and allelopathic potential of roots extracts of Pulicaria odora L, Res. J. Pharm. Biol. Chem. Sci., 2018, 9, 872-882.

10-V.L. Singleton, J.A. Rossi, Colorimetry of Total Phenolics with Phosphomolybdic-

Phosphotungstic Acid Reagent, Am.

J. Enology. Vitic., 1965, 16, 144-158.

11-G. Sudha, M.S. Priya, R.I. Shree,

S. Vadivukkarasi, In vitro free radical scavenging activity of raw Pepino fruit (Solanum muricatum Aiton), Inter. J. Curr. Pharm. Res., 2011, 3, 137-140.

12-R.J. Ruch, S.J. Cheng, J.E. Klaunig, Prevention of cytotoxicity and inhibition of intracellular communication by antioxidant catechins isolated from Chinese green tea, Carcinogenesis., 1989, 10, 1003-1008.

13-M. Oyaizu, Studies on products of browning reactions, antioxidative activities of products of browning reaction prepared from glucosamine, Jpn. J. Nutr., 1986, 44, 307-315.

14-A. Tanveer, M.K. Jabbar, A. Kahliq, A. Matloob, R.N. Abbas, M.M. Javaid, Allelopathic effects of aqueous and organic fractions of Euphorbia dracunculoides lam. On germination and seedling growth of chickpea and wheat, Chil. J. Agr. Res., 2012, 72, 495-501.

15-A. Gulzar, M.B. Siddiqui, Allelopathic effect of Calotropis procera on growth and antioxidant activity of Brassica oleracea var. botrytis, J. Saudi. Soc. Agric. Sci., 2017, 16, 375-382.

16-N.Q.M. Al-Hajj, H. Rashid, S. Al-Hashedi, R. Thabit, H. X. Wang, Total Phenolic Content and Antioxidant, antimicrobial Activity from Some Yemani Plants, J. Eur. Acad. Res., 2014, 4, 10196-10215.

17-P.G. Pietta, Flavonoids as Antioxidants, J. Nat. Prod., 2000, 63, 1035-1042.

18-A. Wojdyło, J. Oszmian'ski, R. Czemerys, Antioxidant activity and phenolic compounds in 32 selected herbs, Food. Chem., 2007, 105, 940-949.

19-G. Clarke, K.N. Ting, C. Wiart, J. Fry, High Correlation of 2,2-diphenyl-1-picrylhydrazyl (DPPH) Radical Scavenging, Ferric Reducing Activity Potential, and Total Phenolic Content Indicates Redundancy in Use of All Three Assays to Screen for Antioxidant Activity of Extracts of Plants from the Malaysian Rainforest, J. Antioxidants., 2013, 2, 1-10.

20-N. Shariatifar, A. Kamkar, M.R. ShamseArdekani, A. Misagi, A. Akhonzade, A.H. Jamshidi, Composition and antioxidant activities of Iranian Pulicaria gnaphalodes essential oil in Soybean oil, Pak. J. Pharm. Sci., 2014, 27, 807-812.

21-N. Djermane, N. Gherraf, R. Arhab, A. Zellagui, K. Rebbas, Chemical composition, antioxidant and antimicrobial activities of the essential oil of Pulicaria arabica (L.), Pharm. Lett., 2016, 8, 1-6.
22-S. Dudonné, X. Vitrac, P. Coutière, M. Woillez, J.M. Mérillon, Comparative study of antioxidant properties and total phenolic content of 30 plant extracts of industrial interest using DPPH, ABTS, FRAP, SOD, and ORAC assays, J. Agric. Food. Chem., 2009, 57, 1768-1774.

23-B.J. Xu, S.H. Yuan, S.K. Chang, Comparative analyses of phenolic composition, antioxidant capacity, and color of cool-season legumes and other selected food legumes, J. Food. Sci., 2007, 72, 167-177.

24-S. Burt, Essential oils their antibacterial properties and potential applications in foods, Int. J. Food. Microbiol., 2004, 94, 223-253.

25-M. Olszowy, A.L. Dawidowicz, Essential oils as antioxidants: their evaluation by DPPH, ABTS, FRAP, CUPRAC, and $\beta$-carotene bleaching methods, Monatsh. Chem., 2016, 147 , 2083-2091.

26-L. De Martino, E. Mancini, A. Marandino, L. Fernando-Rolim, V. De Feo, Chemistry, and Antigerminative Activity of Essential Oils and Monoterpenoids from Mediterranean Plants, Curr. Bioact. Compd., 2012, 8, 13-49.

27-H.R.A. Ghareib, M.S. Abdelhamed, O.H. Ibrahim, Antioxidative effects of the acetone fraction and vanillic acid from Chenopodium murale on tomato plants, Weed. Biol. Manag., 2010, 10, 64-72.

28-S.U. Chon, J.H. Coutts, C.J. Nelson, Effects of light, growth media, and seedling orientation on bioassays of alfalfa autotoxicity, Agron. J., 2000, 92, 715-720.

29-S. Azirak, S. Karaman, Allelopathic effect of some essential oils and components on germination of weed species, Acta. Agric. Scand. B-S P., 2008, 51, 88-92.

30-I. Amri, L. Hamrouni, M. Hanana, B. Jamoussi, Reviews on phytotoxic effects of essential oils and their individual components: news approach for weeds management, Int. J. Appl. Biol. Pharm., 2013, 4, 96-114.

31-S. Kaur, H.P. Singh, S. Mittal, D.R. Batish, R.K. Kohli, Phytotoxic effects of volatile oil from Artemisia scoparia against weeds and its possible use as a bioherbicide, Ind. Crops. Prod., 2010, 32, 54-61.

32-L.F. Rolim de Almeida, F. Frei, E. Mancini, L. De Martino, V. De Feo, Phytotoxic activities of Mediterranean essential oils, Molecules., 2010, 15, 4309-4323.

33-L.G. Angelini, G. Carpanese, P.L. Cioni, I. Morelli, M. Macchia, G. Flamini, Essential Oils from Mediterranean Lamiaceae as Weed Germination Inhibitors, J. Agr. Food. Chem., 2003, 51, 6158-6164.

34-T. Tworkoski, Herbicide effects of essential oils, Weed. Sci., 2002, 50, 425-431.

35-N. Dudai, A. Poljakoff-Mayber, A.M. Mayer, E. Putievsky, H.R. Lerner, Essential oils as allelochemicals and their potential use as bioherbicides, J. Chem. Ecol., 1999, 25, 
1079-1089.

36-A. Synowiec, D. Kalemba, E. Drozdek, J. Bocianowski, Phytotoxic potential of essential oils from temperate climate plants against the germination of selected weeds and crops, J. Pest. Sci., 2016, 90, 407-419.

37-I.B.H. Jilani, S. Chebil, R. Khiari, I. Melki, S. LimamBenSaad, A. Daoud-Bouattour, Z. Gammar-Ghrabi, Allelopathic potential of some essential oils vis-à-vis three noxious weed species invading cereals, Inter. J. Agro. Agric. Res., 2014, 4, 77-97.

38-D. Vokou, P. Douvli, G.J. Blionis, J.M. Halley, Effects of monoterpenoids, acting alone or in pairs, on seed germination and subsequent seedling growth, J. Chem. Ecol., 2003, 29, 2281-2301.

39-S. Kordali, A. Cakir, S. Sutay, Inhibitory effects of monoterpenes on seed germination and seedling growth, Z Naturforsch C., 2007, 62, 207-214.

40-L. De Martino, E. Mancini, R. de Almeida, L.F. De Feo, the Antigerminative Activity of TwentySeven Monoterpenes, Molecules., 2010, 15, 6630-6637.

41-S. Mutlu, Ö. Atici, N. Esim, Bioherbicidal effects of essential oils of Nepeta meyeri Benth on weed spp, Allelopathy. J., 2010, 26, 291-300.

42-M.L. López, N.E. Bonzani, J.A. Zygadlo, Allelopathic potential of Tagetes minuta terpenes by a chemical, anatomical and phytotoxic approach, Biochem. Syst. Ecol., 2009, 36, 882-890.
43-M. Verdeguer, M.A. Blazquez, H. Boira, Phytotoxic effects of Lantana camara, Eucalyptus camaldulensis, and Eriocephalus africanus essential oils in weeds of Mediterranean summer crops, Biochem. Syst. Ecol., 2009, 37, 362-369.

44-E. Rolli, M. Marieschi, S. Maietti, G. Sacchetti, R. Bruni, Comparative phytotoxicity of 25 essential oils on pre and postemergence development of Solanum lycopersicum L.: a multivariate approach, Ind. Crops. Prod., 2014, 60, 280-290.

45-D. Abrahim, W.L. Braguini, A.M. KelmerBracht, E.L. IshiiIwamoto, Effects of four monoterpenes on germination, primary root growth, and mitochondrial respiration of maize, J. Chem. Ecol., 2000, 26, 611-624.

46-H.P. Singh, D.R. Batish, S. Kaur, H. Ramezani, R.K. Kohli, Comparative phytotoxicity of four monoterpenes against Cassia occidentalis, Ann. Appl. Biol., 2002, 141, 111-116.

47-H.P. Singh D.R. Batish, S. Kaur, K. Arora, R.K. Kohli, $\alpha$-pinene inhibits growth and induces oxidative stress in roots, Ann. Bot., 2006, 98, 1261-1269.

48-M. Perricone, E. Arace, M.R. Corbo, M. Sinigaglia, A. Bevilacqua, Bioactivity of essential oils, a review on their interaction with food components, Front. Microbiol., 2015, 6, 76.

49-D. Vokou, Essential oils as allelochemicals: research advances in Greece. In Narwal SS (ed) Allelopathy Update Basic and Applied Aspects, Science., New York, 1999, 2, 47-63. 